\title{
COMPOSTAGEM DE ALGAS ARRIBADAS COMO FERRAMENTA DE EDUCAÇÃO AMBIENTAL EM UMA ESCOLA PÚBLICA
}

\author{
Layanna de Almeida Gomes Bastos ${ }^{1}$ \\ Maria Cristina Basilio Crispim da Silva ${ }^{2}$ \\ Gil Dutra Furtado ${ }^{3}$
}

Resumo: $O$ artigo faz uma comparação na aprendizagem de dois grupos de alunos do sexto ano de uma escola pública de Cabedelo-PB utilizando a compostagem de algas arribadas. A análise foi realizada avaliando a percepção ambiental pela aplicação de questionários em dois momentos: no contato inicial e após uma sensibilização ambiental. Essa sensibilização ocorreu de maneiras diferentes nos grupos: teórica (palestra); e prática (compostagem e horta). Foi possível observar que houve uma melhoria na percepção dos problemas ambientais e maior abrangência nos conceitos de Meio Ambiente e EA, especialmente para o grupo que realizou a atividade de forma prática, evidenciando que a compostagem pode ser usada como ferramenta de EA e que seu uso na prática oferece resultados mais substanciais.

Palavras-chave: Educação Ambiental; Sensibilização; Algas Arribadas.

1 Universidade Federal da Paraíba. E-mail: layannalmeida@hotmail.com.

2 Universidade Federal da Paraíba. E-mail: ccrispim@hotmail.com.

3 Universidade Federal da Paraíba. E-mail: gdfurtado@hotmail.com. 


\section{Introdução}

Vive-se uma crise ambiental sem precedentes, com recursos cada vez mais escassos e consumo cada vez mais elevado, colocando em risco a sobrevivência da nossa espécie e de todas as outras.

Muitos estudos têm sido realizados com o objetivo de avaliar os impactos causados pelo modelo de desenvolvimento capitalista no meio ambiente e formas de amenizar as consequências destes. No entanto, o cerne da questão está em algo mais intrínseco e antigo.

Por muito tempo a humanidade carregou consigo a ideia de que o mundo lhe foi dado como dádiva, que a espécie humana era superior às outras e que a natureza era um recurso inesgotável para a sua subsistência. Tal conduta, oriunda do antropocentrismo, ganhou força no período do lluminismo, quando o humano era considerado senhor da razão e do progresso.

Apenas no século $X X$ com o surgimento da discussão ambiental, apareceu uma nova forma de ver o mundo e surgiu o conceito de Ecocentrismo. Este conceito reflete sobre como as pessoas percebem o meio ambiente e se engajam para cuidar dele, trazendo embutidas questões relacionadas com a ética ecológica (PIRES et al., 2014). Mas apesar de todos os esforços no sentido de desconstruir essa visão, muitos desses conceitos estão fixados na nossa identidade e se manifestam na nossa conduta e ações (MORIN, 2003).

Portanto, para que haja uma efetividade no combate aos desequilíbrios ambientais é necessário primeiramente entender como o homem percebe o meio ambiente e sua relação com o mesmo, para só então propor ações que visem a melhoria da qualidade de vida e a sustentabilidade (SILVA et al., 2014; CABRAL et al., 2015).

Desta forma, a escola é um local privilegiado para analisar a percepção ambiental das futuras gerações e assim repensar as ações que serão necessárias para mitigar os impactos ambientais atuais e futuros (BARCELOS, 2009; REIGOTA, 2010). Através do aumento do conhecimento sobre as questões ambientais o que leva ao aumento de sensibilização para os problemas causados pelos impactos humanos e com isso se consiga mudar as posturas humanas em relação ao meio ambiente.

Ao longo de muitos anos têm sido discutidos novos métodos e estratégias para realizar a Educação Ambiental (EA) de forma eficiente e significativa, pois já é sabido que esta é uma das rotas mais eficazes para a construção de uma sociedade mais justa, igualitária e sustentável.

A EA tem que ser pensada de forma complexa (MORIN, 2004), pois envolve todos os setores da sociedade, todas as disciplinas da escola, todas as mídias e todos os espaços, por isso, é preciso disseminar essa ideia desde a infância, na educação doméstica, nos exemplos do dia-a-dia e dar continuidade, por onde o indivíduo passar, pois a educação é um processo contínuo. Sauvé (2005) afirmou que a EA tem como função criar dinâmicas 
sociais, na comunidade local que depois se propaguem de forma colaborativa a respeito das realidades socioambientais.

Normalmente a EA é trabalhada nas escolas através dos conteúdos expostos nos livros didáticos, especialmente de Ciências, de forma teórica e por muitas vezes descontextualizada da realidade dos educandos (SOARES et al., 2004; MACIEL et al., 2010).

Porém, diante dos problemas ambientais vividos na atualidade o professor vem sendo desafiado a desenvolver novas rotas de aprendizagem para tornar a EA mais efetiva (TÉBAR, 2011). Desta forma, a compostagem surge como uma proposta educativa de fácil acesso, baixo custo e de simples reprodução. Transformando materiais orgânicos disponíveis no ambiente, que eram considerados lixo, em adubo que poderá ser utilizado em uma horta. Despertando o interesse pelas questões ambientais e propondo soluções criativas para um dos maiores problemas ambientais, o lixo.

Neste sentido, o presente estudo propõe investigar se a compostagem pode ser utilizada como ferramenta de EA nas escolas e comparar os resultados de sua aplicação de forma teórica com a forma prática, usando como modelo uma escola pública do município de Cabedelo (PB).

\section{Metodologia}

\section{Universo da Pesquisa}

A pesquisa foi realizada no município de Cabedelo-PB, visto que o local é cercado por praias, com grande número de algas arribadas que atualmente não possuem nenhum aproveitamento pela comunidade local.

Cabedelo (Figura 1) faz parte da Região Metropolitana de João Pessoa e segundo dados do último CENSO realizado pelo IBGE possui uma população estimada de 57.944 habitantes e uma área de $31,915 \mathrm{~km}^{2}$ (IBGE, 2010).

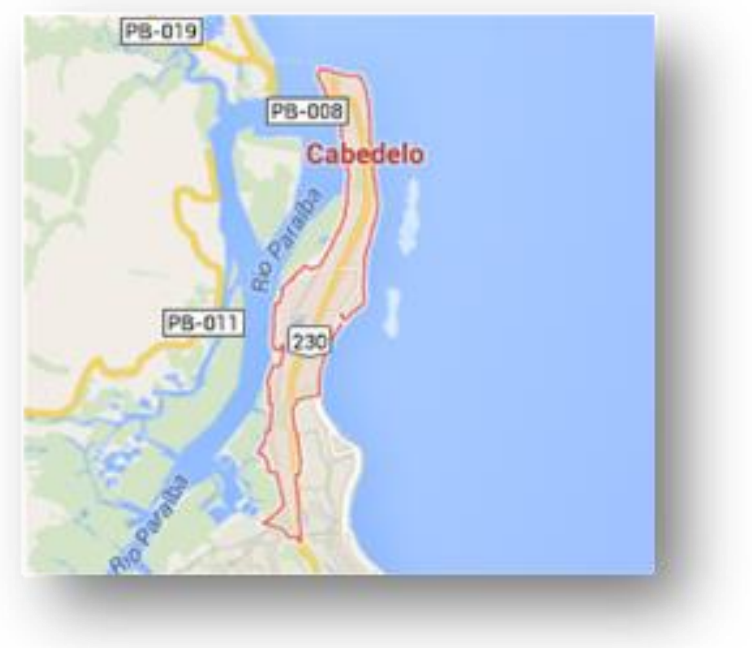

Figura 1: Cidade de Cabedelo. Fonte: Google. 
O bioma predominante é mata atlântica e o clima tropical chuvoso, com temperaturas variando entre $22^{\circ} \mathrm{C}$ e $30^{\circ} \mathrm{C}$. O índice pluviométrico é de aproximadamente $1900 \mathrm{~mm}$ anuais (IBGE, 2016).

As praias que circundam o município são Praia de Miramar, Praia Ponta de Matos, Praia de Areia Vermelha, Praia Formosa, Praia de Areia Dourada, Praia de Camboinha, Praia do Poço, Praia de Intermares e Praia Fluvial do Jacaré. Nelas é comum haver o acúmulo de algas arribadas na região entre marés quando ocorre a maré baixa.

A economia da cidade tem forte relação com a exploração dos seus recursos naturais que atraem muitos turistas para visitar as suas praias, o que movimenta o comércio da região. Nela também está localizado o Porto do Estado e um Moinho que geram emprego e renda de forma direta ou indireta para as famílias da região, bem como receita para o município (MENDES FILHO et al., 2010).

\section{Área de Estudo}

O projeto foi executado na Escola Municipal Maria Pessoa Cavalcanti, localizada na Rua Aderbal Piragibe, s/n, Centro, Cabedelo (PB). A referida escola recebe alunos de todos os bairros de Cabedelo e de municípios vizinhos como Lucena (PB). Funciona nos turnos manhã e tarde com as turmas finais do Ensino Fundamental (6음 ao $9^{\circ}$ ano).

No ano de 2017 a escola possuía o quantitativo de 44 funcionários entre prestadores de serviço e efetivos e 350 alunos distribuídos em 6 turmas no turno manhã e 6 turmas no turno tarde. Para a pesquisa foram selecionados como amostra os alunos do 6을 Ano dos turnos manhã e tarde para trabalharem diretamente com o projeto em todas as suas etapas. Como a pesquisa se estendeu até o ano de 2018 duas turmas de sétimo ano foram contempladas nesse ano, por serem as de sexto ano no ano anterior.

Esta escola foi escolhida por apresentar um representativo número de estudantes residentes no litoral cabedelense, de forma que estes sejam multiplicadores das ideias disseminadas no estudo. As turmas de sextos anos foram selecionadas pelo fato de a temática compostagem estar inserida no seu conteúdo programático e já ter sido trabalhada com eles.

A participação na pesquisa foi acordada com os alunos e seus responsáveis, uma vez que os mesmos são menores de idade. Não obstante, toda a comunidade escolar foi contemplada, pois em algum momento, esteve atuando direta ou indiretamente em alguma atividade desenvolvida no decorrer da pesquisa.

Havia quatro turmas de $6^{\circ}$ ano, sendo duas no turno manhã e duas no turno tarde no ano de 2017, composta por meninas e meninos com idades variando entre 11 e 14 anos. Para a aplicação da metodologia as turmas foram 
divididas em dois grupos os quais convencionou-se chamar de $\mathrm{A}$ e $\mathrm{B}$. Em ambos os grupos foi aplicado um questionário pré-teste, com o objetivo de verificar a percepção ambiental dos alunos antes da sensibilização que foi realizada na pesquisa. $O$ grupo $A$ realizou a compostagem das algas arribadas na escola, observou a produção do adubo, montou uma horta utilizando o adubo que produziram e só então responderam o questionário pós-teste. $\mathrm{O}$ grupo B assistiu a uma palestra sobre EA e compostagem simulando a abordagem tradicional que normalmente é realizada nas aulas, em seguida respondeu ao questionário pós EA. O propósito desta distribuição foi fazer a pesquisa sobre a influência de atividades práticas na $E A$, para além da aplicação da EA. A distribuição das turmas nos grupos está evidenciada no Quadro 1.

Quadro 1: distribuição das turmas de 6ํㅜ ano da Escola Municipal Maria Pessoa Cavalcanti nos dois grupos de pesquisa nos anos de 2017 e 2018.

\begin{tabular}{|c|c|c|c|}
\hline TURMAS & TURNO & QUANTITATIVO DE ALUNOS & GRUPO \\
\hline 6A (2017) / 70 A (2018) & Manhã & 24 & $A$ \\
\hline $6 \div \mathrm{B}$ & Manhã & 20 & $B$ \\
\hline $6^{\circ} \mathrm{C}(2017) / 7^{\circ} \mathrm{C}(2018)$ & Tarde & 26 & $A$ \\
\hline $6 \div D$ & Tarde & 14 & $\mathrm{~B}$ \\
\hline
\end{tabular}

Fonte: Dados da pesquisa

É importante mencionar que o quantitativo de alunos informados no quadro anterior corresponde aos que foram avaliados durante a pesquisa, pois houve alunos que não quiseram participar, ou que os pais não assinaram o termo de consentimento. Estes estavam presentes nas etapas do trabalho, mas não foram avaliados. O período das atividades com os alunos teve início no dia 21/08/2017 e término em 12/06/2018.

\section{Levantamento da percepção ambiental dos alunos}

Um levantamento de dados sobre a percepção ambiental dos alunos foi realizado através da aplicação de questionários com perguntas abertas e fechadas em dois momentos. O primeiro, chamado de pré-teste (Apêndice A), ocorreu no início da pesquisa para verificar o conhecimento prévio dos educandos, enquanto que o segundo, chamado de pós-teste (Apêndice B), foi aplicado ao final da etapa de sensibilização, que ocorreu em momentos distintos para os dois grupos.

Chaer et al. (2011) enumeraram alguns pontos fortes para o uso de questionários nas pesquisas, entre eles pode-se citar, o anonimato, o tempo que as pessoas têm para pensar nas respostas das questões e o baixo custo. 
O pré-teste foi aplicado com os grupos A e B no dia 23/08/2017. O pósteste do grupo $B$ foi realizado em 04/10/2017 logo após a palestra sobre meio ambiente, EA e compostagem, enquanto que o do grupo $A$ foi realizado no dia 12/06/2018 após a vivência da produção do adubo através da compostagem de algas arribadas e sua aplicação em uma horta.

Nestes questionários foram contempladas questões relacionadas com o perfil social dos alunos, conceito de meio ambiente, a importância da EA, lixo e compostagem.

É importante citar que os questionários pré e pós-testes não eram completamente iguais. Algumas questões possuíam similaridade, para que pudessem ser comparadas e outras eram complementares. Esta medida foi adotada para que não houvesse perda de interesse em responder o segundo questionário por parte dos entrevistados.

Foi observada a Resolução 510/2016, no tocante à ética na pesquisa e as autorizações foram assinadas pelos pais/responsáveis uma vez que os alunos são menores de idade.

As informações coletadas foram analisadas por meio da técnica de análise de conteúdo (BARDIN, 2012) que teve por objetivo categorizar os dados disponíveis nos questionários, facilitando a compreensão e comparação dos mesmos. Para os conceitos de meio ambiente utilizou-se como referência as correntes de meio ambiente de Sauvé (2005) e para a EA as categorias de Abílio (2011). Os dados também foram trabalhados de forma quantitativa, apresentados em valores percentuais.

\section{Instrução sobre meio ambiente, EA e compostagem}

$\mathrm{O}$ grupo $\mathrm{A}$ trouxe algas arribadas coletadas próximo as suas residências e no dia 08/11/2017 em trios construíram composteiras de garrafas PET. Cada grupo utilizou duas garrafas PET, uma foi cortada ao meio e a base foi utilizada como coletor de chorume, a outra foi cortada próximo à base e teve seu bico inserido no coletor que havia sido preparado. Foram alternadas camadas de terra e algas no interior da garrafa com espessura de três dedos cada camada, sendo a primeira camada de brita para impedir que a terra e as algas passassem pelo bico da garrafa, permitindo apenas a passagem do chorume. A última camada foi de terra e o material foi umidificado. Ao longo de 30 dias foram realizadas observações por parte dos alunos e sempre que necessário a terra era revolvida e umidificada, após esse período foi observado que o material estava homogêneo e considerado pronto para ser aplicado no solo.

No dia 25/04/2018 foram iniciadas as atividades da horta com uma das turmas do Grupo A, enquanto na outra só foi possível o início no dia 03/05/2018. Foram utilizadas sementes de coentro, alface Mônica, alface americana e acelga, o adubo utilizado foi o que eles haviam produzido com algas arribadas por compostagem. Durante um período de 30 dias foram realizadas observações por parte dos alunos sobre a germinação das

revista brasileira educação ambiental 
hortaliças e o seu desenvolvimento. Havia um grupo controle que não recebeu adubo e serviu de comparação para as observações.

O grupo B assistiu a uma palestra ministrada no dia 04/10/2017, que teve a duração de 60 minutos, na qual utilizou-se como recurso pedagógico o Datashow através do qual foram projetados uma apresentação de slides que continha textos, imagens e vídeos com o objetivo de trabalhar a temática do meio ambiente, a importância da EA e de que forma a compostagem pode auxiliar nesse processo. A linguagem utilizada foi acessível e os temas eram associados à realidade local de modo a facilitar a compreensão dos alunos.

\section{Resultados e discussão}

\section{Análise do grupo A}

Verificou-se que haviam 26 meninos e 24 meninas dos quais $42 \%$ nasceram em Cabedelo, $19 \%$ em João Pessoa e 39\% em outras cidades. Desses, $32 \%$ residem no centro de Cabedelo, os demais (68\%) moram em bairros próximos como Intermares, Camboinha e Jacaré ou na cidade vizinha Lucena-PB.

Pudemos observar que a maioria (64\%) possui dois ou mais irmãos. Quando questionados sobre a religião $48 \%$ afirmaram ser católicos, $20 \%$ evangélicos, $2 \%$ Testemunhas de Jeová e $30 \%$ não possuem ou não informaram.

Sobre o futuro profissional conforme mostra a Figura 2 a profissão que teve o maior número de citações foi jogador de futebol (13\%), seguido daqueles que não sabem ou não informaram (12\%). Esta informação revela que muitos adolescentes ainda não decidiram o seu futuro profissional, seja pelas dúvidas que são peculiares à idade ou por estarem desacreditados de suas capacidades para desempenhar alguma profissão e, por isso, muitas vezes, se espelham em ídolos que, em sua maioria, saíram da periferia e hoje ganham destaque na mídia e são bem remunerados como os jogadores de futebol. Destacamos também o surgimento de novas profissões como youtuber (6\%) que com o crescente sucesso das plataformas digitais, tem ganho destaque na mídia e no imaginário desses educandos. 


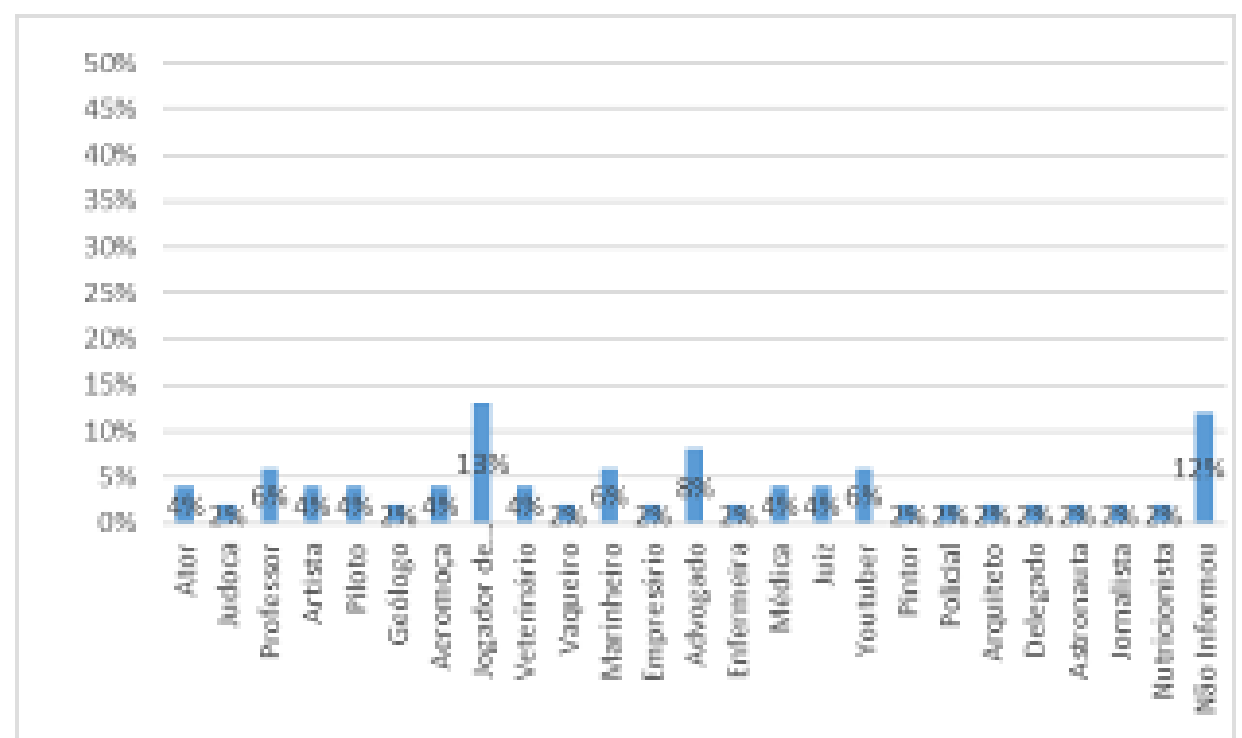

Figura 2: Gráfico das profissões que os respondentes do grupo A da Escola Municipal Maria Pessoa Cavalcanti pretendem exercer no futuro. Fonte: dados da pesquisa.

Além dessas questões sociais foram realizadas perguntas para avaliar a percepção ambiental dos alunos com relação a EA, ao meio ambiente e ao lixo. Com o objetivo de comparar se houve uma mudança nas respostas após terem trabalhado com a horta escolar.

No questionário pré-teste quando questionados se todos os resíduos que são descartados no lixo não têm mais uso $36 \%$ responderam que sim, ou seja, tudo que era descartado não pode ser reaproveitado; $38 \%$ responderam que não, ou seja, no lixo existe materiais passíveis de reaproveitamento; $26 \%$ não sabem ou não responderam. Em um trabalho realizado por Leite et al. (2018) numa escola do agreste paraibano verificou-se que $52 \%$ dos alunos consideram que todo o material descartado é lixo. No questionário pós-teste perguntamos se no lixo que é descartado encontramos algum material que ainda tenha utilidade $86 \%$ responderam que sim, $8 \%$ responderam que não e $6 \%$ não sabem ou não responderam. Tal evidência demonstra que houve uma mudança significativa na percepção daquilo que é considerado sem uso e do que pode ser reaproveitado.

Também foi realizado um comparativo dos itens que eles consideram lixo (questionário pré-teste) com aqueles que eles acreditam que pode ser reaproveitado (questionário pós-teste). Como resultado obtivemos as informações que estão representadas na Figura 3. 


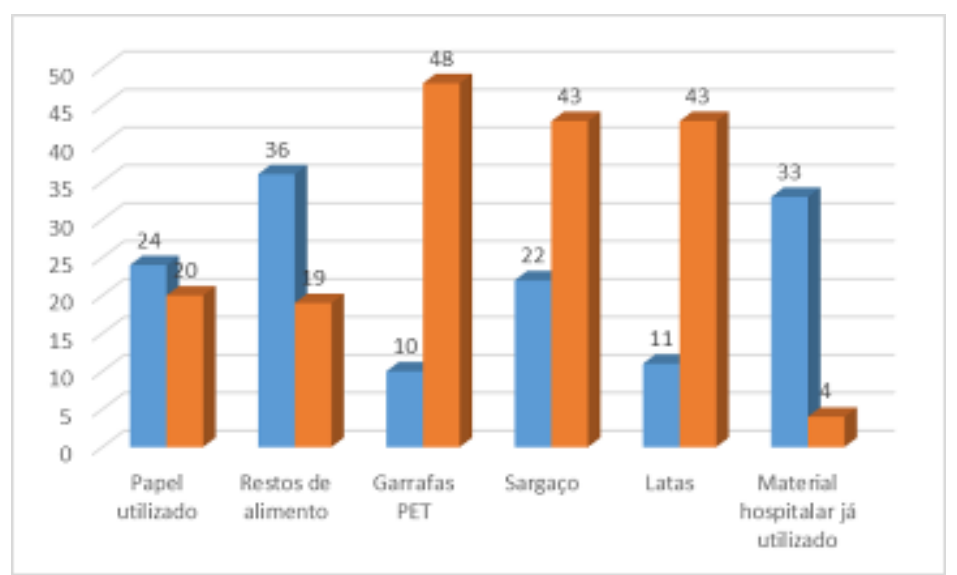

Figura 3: Frequência com que os alunos do grupo A da Escola Municipal Maria Pessoa Cavalcanti informaram no questionário pré-teste o que consideravam lixo (coluna azul) em comparação ao que consideram que pode ser reaproveitado no questionário pós (coluna laranja). Fonte: dados da pesquisa.

Ao observar a imagem pudemos verificar que os itens mais citados como possíveis de reaproveitamento no questionário pós-teste foram as garrafas PET, sargaço e latas. Tal situação pode ser justificada pelo uso das garrafas e do sargaço na horta, podendo justificar a mudança da percepção do que antes parecia sem uso para algo utilizável.

$\mathrm{Na}$ aplicação do questionário pré-teste os alunos foram questionados sobre compostagem, $94 \%$ disseram não saber o que é e apenas $6 \%$ conheciam o termo, apesar deste assunto estar contido no livro de Ciências do $6^{\circ}$ ano adotado pela escola. Mesmo os que disseram conhecer, ao assinalar uma lista de materiais que poderiam ser utilizados para compostagem eles não marcaram restos de alimento nem sargaço, demonstrando um conhecimento superficial sobre o assunto. Já no questionário pós-teste $80 \%$ afirmaram que a compostagem é importante para o meio ambiente e ao assinalar a lista de materiais para fazer compostagem $96 \%$ marcaram sargaço e $58 \%$ restos de alimento. Ressaltando a importância de trabalhar os conteúdos de forma aplicada, pois a simples reprodução do conteúdo contido no livro didático não tem surtido os efeitos esperados de aprendizagem, Oliveira et al (2018), ao realizarem um trabalho com horta escolar também identificaram uma melhor aprendizagem de temas relacionados com as disciplinas de Ciências, Matemática e Português.

A forma como os educandos veem o meio ambiente foi analisada de acordo com Sauvé (2005). No questionário pré-teste 41 entrevistados (82\%) conseguiram dar um conceito para Meio Ambiente, enquanto que $9(18 \%)$ não responderam. A maioria das respostas (78\%) se enquadram na corrente naturalista que traz como característica a referência à natureza através dos termos árvore, planta, floresta, desassociando o ser humano. Em um estudo sobre percepção ambiental numa escola da llha do Marajó (PA) também se verificou que a maioria dos entrevistados $(42,7 \%)$ apresentaram um conceito 
naturalista para o meio ambiente (REPOLHO et al., 2018). Tal comportamento é prejudicial ao meio ambiente, pois a partir do momento em que o homem não se sente parte do meio, não o valoriza como necessário.

As outras correntes citadas tiveram porcentagens menos expressivas e estão representadas no Quadro 2, sendo elas: a conservacionista que traz a ideia de preservação/conservação dos recursos; a resolutiva que tende a focar nos problemas ambientais; e a holística que tem uma visão do meio ambiente como o todo. Outros apresentaram conceitos confusos que não puderam ser enquadrados em nenhuma das categorias.

Quadro 2: respostas dos alunos do grupo A da Escola Municipal Maria Pessoa Cavalcanti no questionário Pré-teste sobre o conceito de Meio Ambiente, categorizadas segundo Sauvé (2005).

\begin{tabular}{|c|c|c|c|}
\hline \multirow[t]{2}{*}{ CORRENTES } & \multirow[t]{2}{*}{ EXEMPLOS } & \multicolumn{2}{|c|}{ ABUNDÂNCIA } \\
\hline & & Total & Relativa \\
\hline Naturalista & $\begin{array}{l}\text { "Animais e plantas porque são seres naturais" } \\
\text { "Plantas e animais porque fazem parte da } \\
\text { natureza" } \\
\text { "Plantas porque a mata tem muita planta" } \\
\text { "Só planta tem no ambiente" } \\
\text { "Plantas porque as plantas são da natureza" }\end{array}$ & 31 & $78 \%$ \\
\hline Conservacionista & $\begin{array}{l}\text { "É o ambiente preservado" } \\
\text { "Temos que cuidar das plantas, arrancaram, } \\
\text { planta outra" } \\
\text { "Porque temos que preservar a natureza e } \\
\text { respeitar os animais" }\end{array}$ & 3 & $7 \%$ \\
\hline Resolutiva & $\begin{array}{l}\text { "São os lixos reciclados" } \\
\text { "São reciclagem que eu acho que faz parte do } \\
\text { meio ambiente" }\end{array}$ & 2 & $5 \%$ \\
\hline Holística & $\begin{array}{l}\text { "O meio ambiente não são só plantas e sim } \\
\text { animais, árvores, frutos, rios etc..." } \\
\text { "Meio ambiente pra mim é tudo aquilo que eu } \\
\text { vejo na rua" }\end{array}$ & 2 & $5 \%$ \\
\hline Confuso & $\begin{array}{l}\text { "Tudo que tem de importante na natureza" } \\
\text { "O ser humano porque sem nós não haveria } \\
\text { meio ambiente" }\end{array}$ & 2 & $5 \%$ \\
\hline & & 41 & $100 \%$ \\
\hline
\end{tabular}

Fonte: Dados da pesquisa.

No questionário pós-teste 48 alunos, que representam $96 \%$ dos entrevistados, conseguiram elaborar um conceito para meio ambiente e apenas 2 alunos, que representam 4\%, não o fizeram. Dos que responderam, $37 \%$ foram classificadas como naturalistas, demonstrando que apesar do menor índice em relação ao pré-teste, este é um conceito que está interiorizado e, por isso, faz-se necessário maiores esforços para expandir a visão das pessoas no tocante ao meio ambiente e o seu papel nele.

Também pode-se verificar um maior espectro de conceitos quando comparado com o pré-teste, com o aparecimento de novas categorias como a biorregionalista que faz referência ao meio como lugar de pertença e a 
moral/ética que traz consigo uma relação de valores e sentimentos pelo meio ambiente. Assim como, visualiza-se um aumento da quantidade de pessoas que elaboraram respostas enquadradas nas categorias resolutiva e holística conforme pode-se verificar no Quando 3.

Quadro 3: respostas dos alunos do grupo A da Escola Municipal Maria Pessoa Cavalcanti no questionário Pós-teste sobre o conceito de Meio Ambiente, categorizadas segundo Sauvé (2005).

\begin{tabular}{|c|c|c|c|}
\hline \multirow[t]{2}{*}{ CORRENTES } & \multirow[t]{2}{*}{ EXEMPLOS } & \multicolumn{2}{|c|}{ ABUNDÂNCIA } \\
\hline & & Total & Relativa \\
\hline Naturalista & $\begin{array}{l}\text { "São árvores e animais que utilizam a natureza" } \\
\text { "É a natureza limpa" } \\
\text { "São as árvores, sargaços, plantas e etc" } \\
\text { "As matas e os ambientes" } \\
\text { "É um lugar lindo cheio de árvores com flores" }\end{array}$ & 18 & $37 \%$ \\
\hline Conservacionista & $\begin{array}{l}\text { "Porque o meio ambiente tem que ser cuidado por } \\
\text { causa da terra" } \\
\text { "Preservar a natureza" } \\
\text { "É um espaço natural preservado" }\end{array}$ & 3 & $6 \%$ \\
\hline Resolutiva & $\begin{array}{l}\text { "Uma forma de deixar o ambiente limpo" } \\
\text { "Tudo que for de bom que não deixa o mundo cheio } \\
\text { de lixo" } \\
\text { "É um nome utilizado para quando coletamos, } \\
\text { reciclamos ou reutilizamos" } \\
\text { "É tudo aqui que a gente vive só que sem lixo" }\end{array}$ & 9 & $19 \%$ \\
\hline Holística & $\begin{array}{l}\text { "É tudo a nossa volta, os rios, as florestas, as praias, } \\
\text { as lagoas, os seres vivos etc..." } \\
\text { "O nosso planeta" } \\
\text { "É um ambiente que não tem só vegetação, quantos } \\
\text { animais, seres vivos que necessitam desse } \\
\text { ambiente pra sua sobrevivência" } \\
\text { "É tudo aquilo que a gente pode alcançar com o } \\
\text { foco da nossa visão" }\end{array}$ & 9 & $19 \%$ \\
\hline Biorregionalista & $\begin{array}{l}\text { "É onde vivemos" } \\
\text { "Lugar aonde se convive os seres" } \\
\text { "É um lugar que tem que ser cuidado" }\end{array}$ & 7 & $15 \%$ \\
\hline Moral/Ética & "Para mim meio ambiente é o coração de tudo" & 1 & $2 \%$ \\
\hline Confuso & $\begin{array}{l}\text { "Nós devemos muita coisa e as promessas que } \\
\text { todos fez não faz" }\end{array}$ & 1 & $2 \%$ \\
\hline & & 48 & $100 \%$ \\
\hline
\end{tabular}

Fonte: Dados da pesquisa

A discussão sobre os tipos de EA é muito grande. No III Fórum Social Mundial que aconteceu em porto Alegre em 2003, o autor Fritjot Capra enunciou que haviam muitas educações ambientais no Brasil. Segundo Carvalho não é tarefa fácil se posicionar por uma das categorias de EA nem tão pouco reunir os múltiplos conceitos elaborados, formando uma única $E A$ (CARVALHO, 2004).

Sendo assim, no que diz respeito ao nosso estudo, decidimos teste $74 \%$ dos alunos conseguiram elaborar um conceito para EA, enquanto Revbea, São Paulo, V. 14, № 1: 416-438, 2019. 
$26 \%$ não. Dos que responderam $40 \%$ se enquadram na categoria resolutiva que delega à EA a solução para os problemas ambientais; $24 \%$ em disciplina pois enxergam-na como disciplina curricular; $22 \%$ em sensibilização pois remetem a uma ideia de cuidado com o meio ambiente; $8 \%$ preservacionista que valoriza o processo de preservação dos recursos; $3 \%$ generalista pois apresenta uma visão ampla e confusa sobre os conteúdos; $3 \%$ desenvolvimento sustentável quando apresenta uma preocupação com as gerações futuras. Alguns exemplos das respostas categorizadas estão apresentados no Quadro 4.

Quadro 4: respostas dos alunos do grupo A da Escola Municipal Maria Pessoa Cavalcanti no questionário Pré-teste sobre o conceito de Educação Ambiental, categorizadas segundo Abílio (2011).

\begin{tabular}{|c|c|c|c|}
\hline \multirow{2}{*}{$\begin{array}{l}\text { CATEGORIAS } \\
\text { DE EA }\end{array}$} & \multirow[t]{2}{*}{ EXEMPLOS } & \multicolumn{2}{|c|}{ ABUNDÂNCIA } \\
\hline & & Total & Relativa \\
\hline Resolutiva & $\begin{array}{l}\text { "É não jogar lixo, não poluir e etc" } \\
\text { "Saber o que é reutilizável e o que não é" } \\
\text { "É o reconhecimento de fazer limpeza, reutilizar, } \\
\text { não jogar lixo no chão e etc" } \\
\text { "Jogar o lixo no lixo" }\end{array}$ & 15 & $40 \%$ \\
\hline Disciplina & $\begin{array}{l}\text { "É ensinando a preservar a natureza" } \\
\text { "É quando alguém aprende sobre a natureza" } \\
\text { "Ensinar o que é o ambiente" } \\
\text { e muito mais" }\end{array}$ & 9 & $24 \%$ \\
\hline Sensibilização & $\begin{array}{l}\text { "Respeitar o ambiente" } \\
\text { "É ser educado com o meio ambiente" } \\
\text { "É para cuidar da natureza e dos animais e para } \\
\text { deixar o mundo melhor" } \\
\text { "É cuidar da natureza como se fosse um filho" }\end{array}$ & 8 & $22 \%$ \\
\hline Preservacionista & $\begin{array}{l}\text { "Preservar este mundo" } \\
\text { "É as pessoas preservando e dando soluções para } \\
\text { natureza" } \\
\text { "É o ambiente preservado" }\end{array}$ & 3 & $8 \%$ \\
\hline Generalista & $\begin{array}{l}\text { "É uma coisa que fala sobre várias coisas sobre o } \\
\text { ambiente" }\end{array}$ & 1 & $3 \%$ \\
\hline \multirow[t]{2}{*}{$\begin{array}{l}\text { Desenvolvimento } \\
\text { Sustentável }\end{array}$} & "Ecossistema e desenvolvimento sustentável" & 1 & $3 \%$ \\
\hline & & 37 & $100 \%$ \\
\hline
\end{tabular}

Fonte: Dados da pesquisa

No questionário pós-teste $96 \%$ dos entrevistados conseguiram construir um conceito para EA, enquanto apenas $4 \%$ não. Dentre as categorias reconhecidas verificam-se praticamente as mesmas do pré-teste com 0 acréscimo apenas da conservacionista com pouca representatividade (2\%) que valoriza a conservação dos recursos naturais. Teve-se também uma resposta confusa (2\%) a qual não foi possível enquadrar em nenhuma das categorias propostas por Abílio (2011). No entanto, pode-se destacar uma maior distribuição dos conceitos nas categorias, com um aumento da categoria de sensibilização (29\%) indicando que os alunos estão mais atentos à importância 
da EA no cuidado com o meio ambiente, apesar de que a maior abundância ainda foi da resolutiva (38\%), mostrando que os problemas ambientais são uma temática recorrente no imaginário desses jovens e que para eles a EA é a maneira de solucioná-los, conforme pode-se verificar no Quadro 5.

Quadro 5: respostas dos alunos do grupo A da Escola Municipal Maria Pessoa Cavalcanti no questionário Pós-teste sobre o conceito de Educação Ambiental, categorizadas segundo Abílio (2011).

\begin{tabular}{|c|c|c|c|}
\hline \multirow{2}{*}{$\begin{array}{l}\text { CATEGORIAS } \\
\text { DE EA }\end{array}$} & \multirow[t]{2}{*}{ EXEMPLOS } & \multicolumn{2}{|c|}{ ABUNDÂNCIA } \\
\hline & & Total & Relativa \\
\hline Resolutiva & $\begin{array}{l}\text { "Para não produzir doenças e para não poluir nossa } \\
\text { cidade" } \\
\text { "Cuidar das praias e não jogar lixo para os peixes } \\
\text { não morrer" } \\
\text { "Lembrar as pessoas que reaproveitar é bom" } \\
\text { "Ajuda a não jogar lixo na rua" }\end{array}$ & 18 & $38 \%$ \\
\hline Disciplina & $\begin{array}{l}\text { "Aprendemos mais sobre o ambiente o que nós não } \\
\text { sabemos" } \\
\text { "Ensina a cuidar do meio ambiente" } \\
\text { "Para que nós possamos saber o que é certo" } \\
\text { "Para ensinar as pessoas a reutilizar coisas como } \\
\text { garrafa PET, latas etc" }\end{array}$ & 8 & $17 \%$ \\
\hline Sensibilização & $\begin{array}{l}\text { "Respeitar a natureza" } \\
\text { "É importante para aprendermos a cuidar do meio } \\
\text { ambiente" } \\
\text { "O cuidado com o meio ambiente também faz a } \\
\text { gente ficar bem" } \\
\text { "Para termos um meio ambiente melhor, ter uma } \\
\text { vida melhor" }\end{array}$ & 14 & $29 \%$ \\
\hline Preservacionista & $\begin{array}{l}\text { "Você tendo estudo disso pode preservar o meio } \\
\text { ambiente" } \\
\text { "Ajuda a preservar o meio ambiente, se não ele não } \\
\text { vai existir" }\end{array}$ & 2 & $4 \%$ \\
\hline Generalista & $\begin{array}{l}\text { "É o melhor para o meio ambiente" } \\
\text { "É importante assim como para o ambiente e para a } \\
\text { gente seres vivos" }\end{array}$ & 2 & $4 \%$ \\
\hline $\begin{array}{l}\text { Desenvolvimento } \\
\text { Sustentável }\end{array}$ & $\begin{array}{l}\text { "Para sobreviver no futuro" } \\
\text { "Influencia os jovens que vão ser nosso futuro" }\end{array}$ & 2 & $4 \%$ \\
\hline Conservacionista & "Ajuda muito na conservação do meio ambiente" & 1 & $2 \%$ \\
\hline Confuso & "Isso mostrará como isso é importante" & 1 & $2 \%$ \\
\hline & & 48 & $100 \%$ \\
\hline
\end{tabular}

Fonte: Dados da pesquisa.

\section{Análise do grupo B}

Inicialmente traçou-se o perfil social dos educandos pelo qual pode-se verificar que haviam 23 meninos e 11 meninas. Destes, $59 \%$ nasceram em João Pessoa, $21 \%$ em Cabedelo e $20 \%$ em outras cidades. A maioria deles reside no centro da cidade de Cabedelo (65\%), enquanto os demais $(35 \%)$, moram em bairros próximos como Jacaré e Camboinha, ou na cidade vizinha Lucena (PB).

Revbea, São Paulo, V. 14, № 1: 416-438, 2019. 
No geral veem de famílias numerosas, quando questionados sobre o número de irmãos $71 \%$ afirmaram ter 2 ou mais irmãos. A religião predominante é a católica, representada por $38 \%$ dos entrevistados, seguida da evangélica com 24\%, 9\% disseram não possuir religião, enquanto 29\% não informaram.

No tocante ao futuro profissional a maioria respondeu que gostaria de ser jogador de futebol (38\%), enquanto que $9 \%$ não respondeu. As demais profissões informadas estão expressas na Figura 4.

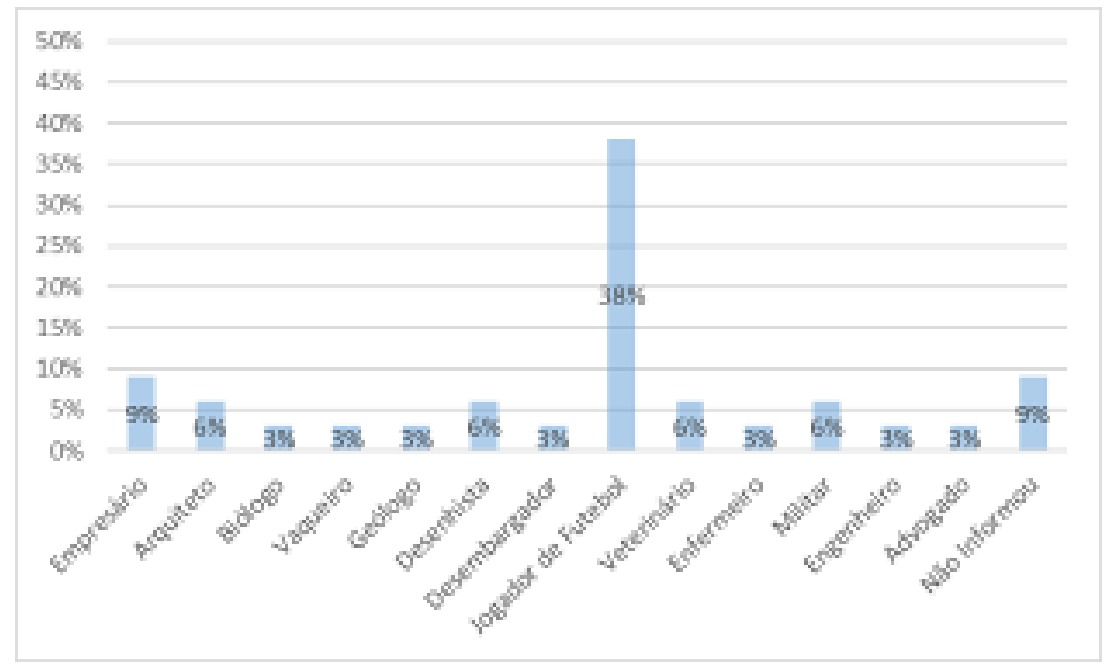

Figura 4: Profissões que os respondentes do grupo B da Escola Municipal Maria Pessoa Cavalcanti pretendem exercer no futuro. Fonte: Dados da pesquisa.

Em relação às profissões é preocupante o fato da maior parte dos questionados alegarem ser jogador de futebol a profissão desejada, porque isso demonstra o quanto almejam algo que gera muita renda, mas que recebe poucas pessoas no seu quadro, na busca por um atalho mágico à profissionalização. Isso remete para outra questão que é a não valorização de profissões que requerem a profissionalização através dos estudos, o que pode ser um dos motivos da baixa motivação dos alunos para o ensino e da subvalorização da educação.

Em seguida, foram feitas perguntas para averiguar $o$ conhecimento destes alunos sobre o lixo, compostagem, meio ambiente e EA, em dois momentos distintos, antes e depois da palestra.

O acúmulo de lixo é um problema que cresce com o passar dos anos, a sociedade tem desperdiçado uma quantidade enorme de matéria prima que poderia ser reaproveitada e, assim, diminuir os impactos na natureza que já está com os recursos naturais escassos (OLIVEIRA et al., 2012). Dessa forma, toda a discussão que levante estas questões, para mostrar aos alunos os problemas gerados e as formas de solucioná-los são necessárias.

Quando questionados se todos os resíduos que são descartados no lixo não têm mais uso, obteve-se o seguinte perfil de respostas. No questionário 
pré-teste $38 \%$ responderam que sim, ou seja, que todos os resíduos descartados não têm mais uso, $53 \%$ responderam que não e que, portanto, existe algum resíduo que pode ser reaproveitado no lixo e $9 \%$ afirmam não saber a resposta. Já no questionário pós-teste apenas 15\% responderam que sim, $79 \%$ responderam que não e $6 \%$ não sabem. Observa-se que houve uma mudança na percepção do que está sendo desperdiçado no lixo e que poderia, então, ser reaproveitado. Silva et al. (2014) em um trabalho com estudantes do Ensino Fundamental sobre a temática do lixo evidenciaram uma melhoria na percepção dos alunos no que diz respeito ao reaproveitamento de resíduos e o seu papel como modificador do meio ambiente.

No questionário pré-teste havia uma lista de materiais para os quais eles deveriam assinalar os que consideram lixo (sem uso), enquanto que no questionário pós a mesma lista estava disponível, no entanto, era questionado quais daqueles materiais poderiam ser reaproveitados, conforme demonstrado na Figura 5.

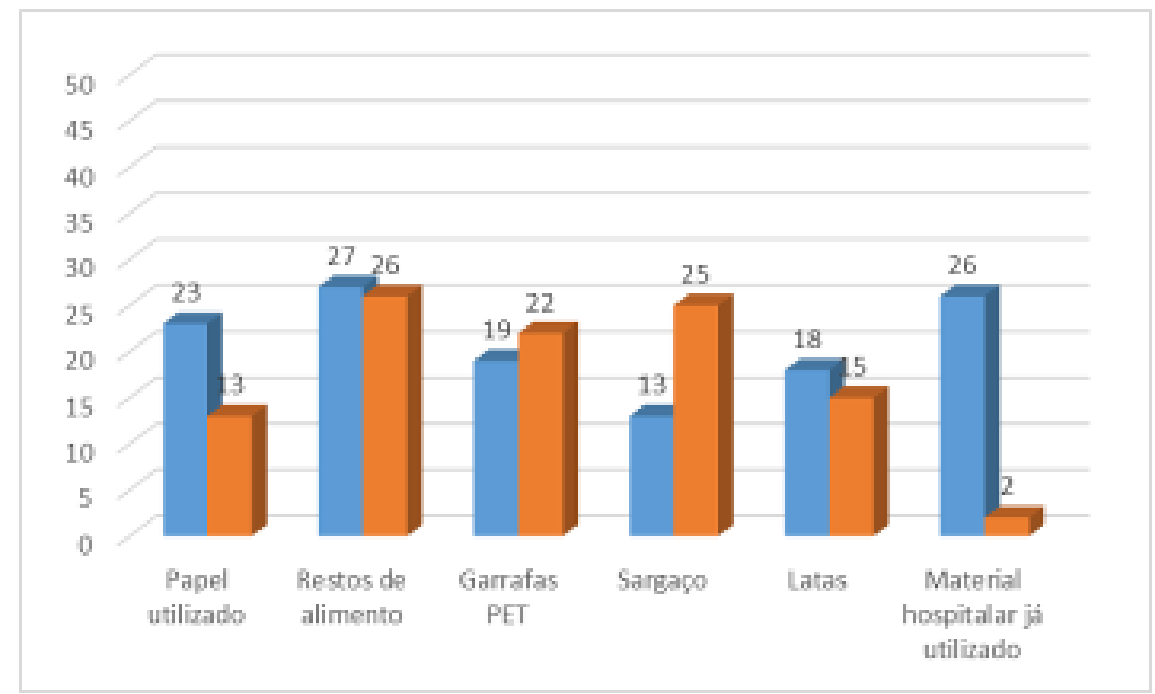

Figura 5: Frequência com que os alunos do grupo B da Escola Municipal Maria Pessoa Cavalcanti informaram no questionário pré-teste o que consideravam lixo (coluna azul) em comparação com o que consideram que pode ser reaproveitado no questionário pós (coluna laranja). Fonte: Dados da pesquisa

Pode-se observar que materiais como garrafas pet, sargaço e restos de alimento que os alunos consideravam lixo, na primeira avaliação, foram os mais indicados como possíveis de reaproveitamento. Demonstrando que houve uma mudança na percepção de quais materiais podem ser reutilizados.

No primeiro momento (questionário pré-teste) apenas $26 \%$ dos entrevistados afirmaram saber o que era compostagem, enquanto $74 \%$ desconheciam o termo, assim como, em uma lista de materiais supostamente possíveis de fazer compostagem, somente $12 \%$ citaram restos de alimentos e $6 \%$ indicaram sargaço. No entanto, no questionário pós-teste $88 \%$ não só reconhecem o seu significado, mas a consideram importante para o meio 
ambiente e $82 \%$ assinalaram restos de alimento como material para compostagem e $79 \%$ o sargaço. Tais resultados evidenciam que a sensibilização teve um efeito positivo no tocante à percepção sobre compostagem.

O questionamento com relação ao conceito de meio ambiente foi analisado segundo Sauvé (2005). No questionário pré-teste $74 \%$ dos entrevistados apresentaram um conceito para meio ambiente, enquanto $26 \%$ não. Das respostas auferidas pode-se observar que houve predominância da corrente de pensamento naturalista $(80 \%)$ em que se pode observar que as respostas se concentram nos termos plantas animais e natureza. Sendo assim, pode-se verificar que o conceito está incompleto, pois não insere os seres humanos e as modificações que ele realiza no ambiente. Para Reigota (1995) a conceituação de meio ambiente como natureza mostra um distanciamento entre o homem e esta, o homem não se sente parte do meio ambiente, o que justifica a exploração dos recursos de forma desmedida.

Outra corrente que foi citada foi a conservacionista (20\%) que tende a ver o meio ambiente como recurso e que por isso deve ser preservado. Também pode estar associado a uma visão de natureza intocada, distante dos seres humanos.

Alguns exemplos das respostas que foram categorizadas nas correntes anteriormente descritas podem ser verificados no Quadro 6.

Quadro 6: respostas dos alunos do grupo B da Escola Municipal Maria Pessoa Cavalcanti no questionário Pré-teste sobre o conceito de Meio Ambiente, categorizadas segundo Sauvé (2005).

\begin{tabular}{|c|c|c|c|}
\hline CORRENTES & EXEMPLOS & \multicolumn{2}{|c|}{ FREQUÊNCIA } \\
\hline Naturalista & $\begin{array}{l}\text { "As plantas porque é importante para a nossa } \\
\text { natureza." } \\
\text { "Meio ambiente cuida da planta." } \\
\text { "A junção de animais e plantas." }\end{array}$ & 20 & $80 \%$ \\
\hline Conservacionista & $\begin{array}{l}\text { "Para preservar a natureza" } \\
\text { "A natureza e os animais sem ser interrompido } \\
\text { pelos humanos." }\end{array}$ & 5 & $20 \%$ \\
\hline & & 25 & $100 \%$ \\
\hline
\end{tabular}

Fonte: Dados da pesquisa.

No questionário pós-teste $76 \%$ dos alunos conseguiram elaborar um conceito para meio ambiente e $24 \%$ não. Quando comparado com o questionário pré-teste mostra um pequeno aumento no quantitativo dos que conseguiram formular um conceito, no entanto, houve uma maior distribuição das respostas nas correntes de meio ambiente, demonstrando uma ampliação da visão destes educandos.

A corrente naturalista ainda é predominante, mas agora em $42 \%$ das respostas, enquanto que a conservacionista está presente em $19 \%$. Abílio et al (2010) em um estudo com alunos do curso de Pedagogia também verificaram que a maioria das repostas sobre o conceito de Meio Ambiente se enquadrava 
na categoria naturalista. Este comportamento é justificado pelo fato destes conceitos já estarem internalizados nos educandos e, desta forma, torna-se mais difícil descontruir para elaborar um mais complexo.

Outras duas categorias foram observadas a biorregionalista (12\%) que tende a elucidar o meio ambiente como um lugar e a resolutiva (27\%) que foca nos problemas ambientais. A representatividade da categoria resolutiva pode ser explicada pelo fato de na palestra que foi ministrada terem sido apresentados vários problemas ambientais, em especial, a questão do lixo. Estes aspectos podem ter influenciado os alunos a visualizarem o meio ambiente como problema. Pode-se ver alguns exemplos no Quadro 7.

Quadro 7: com as respostas dos alunos do grupo B da Escola Municipal Maria Pessoa Cavalcanti no questionário Pós-teste sobre o conceito de Meio Ambiente, categorizadas segundo Sauvé (2005).

\begin{tabular}{|l|l|l|l|}
\hline \multicolumn{1}{|c|}{ CORRENTES } & \multicolumn{1}{|c|}{ EXEMPLOS } & \multicolumn{1}{|c|}{ ABUNDÂNCIA } \\
\cline { 2 - 4 } & \multicolumn{1}{|c|}{ Total } & Relativa \\
\hline Naturalista & $\begin{array}{l}\text { "As florestas, o mar, o rio" } \\
\text { "Florestas, tudo que é natural e está na } \\
\text { natureza" } \\
\text { "A natureza" }\end{array}$ & 11 & $42 \%$ \\
\hline Conservacionista & $\begin{array}{l}\text { "É cuidar do ambiente e respeitá-lo" } \\
\text { "É a preservação do nosso planeta" } \\
\text { "Preservar a natureza" }\end{array}$ & 5 & $19 \%$ \\
\hline Resolutiva & $\begin{array}{l}\text { "Meio ambiente é uma coisa para limpar o } \\
\text { "É quando você não jogar lixo na rua" } \\
\text { "É aproveitar o resto do lixo e do alimento" }\end{array}$ & 7 & $27 \%$ \\
\hline Biorregionalista & $\begin{array}{l}\text { "O meio ambiente é onde nós vivemos" } \\
\text { "É a natureza e o espaço em que você vive" }\end{array}$ & 3 & $12 \%$ \\
\hline & & 26 & $100 \%$ \\
\hline
\end{tabular}

Fonte: Dados da pesquisa.

No tocante à EA as respostas foram categorizadas e avaliadas segundo Abílio (2011). No questionário pré-teste $53 \%$ dos alunos conseguiram formular um conceito para EA, enquanto que $47 \%$ não. Na maioria das respostas (78\%) a EA é vista como resolutiva, ou seja, capaz de resolver os problemas do mundo atual. Para $17 \%$ dos entrevistados ela se encaixa na categoria de sensibilização, possuindo o papel de sensibilizar os indivíduos quanto aos problemas ambientais e, com isso, utilizar os recursos de forma equilibrada. Uma das respostas, que representou $1 \%$ do total, foi enquadrada na categoria de desenvolvimento sustentável, pois mostrou uma preocupação em relação às gerações futuras, como pode ser observado no Quadro 8. 
Quadro 8: com as respostas dos alunos do grupo B da Escola Municipal Maria Pessoa Cavalcanti no questionário Pré-teste sobre o conceito de Educação Ambiental, categorizadas segundo Abílio (2011).

\begin{tabular}{|c|c|c|c|}
\hline \multirow[t]{2}{*}{ CATEGORIAS DE EA } & \multirow[t]{2}{*}{ EXEMPLOS } & \multicolumn{2}{|c|}{ ABUNDÂNCIA } \\
\hline & & Total & Relativa \\
\hline Resolutiva & $\begin{array}{l}\text { "Não jogar lixo na rua não queimar lixo" } \\
\text { "É que não suja o mundo e floresta e etc..." } \\
\text { "Saber colocar o lixo no seu devido lugar" }\end{array}$ & 14 & $78 \%$ \\
\hline Sensibilização & $\begin{array}{l}\text { "Aprender a evitar maltratos ao meio ambiente" } \\
\text { "E todas as pessoas ajudam o ambiente" }\end{array}$ & 3 & $17 \%$ \\
\hline $\begin{array}{l}\text { Desenvolvimento } \\
\text { Sustentável }\end{array}$ & $\begin{array}{l}\text { "Aquela que ensina a não jogar lixo na natureza } \\
\text { e também fala para gente pensar no próximo } \\
\text { exemplo: filhos" }\end{array}$ & 1 & $6 \%$ \\
\hline & & 18 & $100 \%$ \\
\hline
\end{tabular}

Fonte: Dados da pesquisa.

Ao analisar o questionário pós-teste observa-se que $56 \%$ do total conseguiu apresentar um conceito para EA, já 44\% não informaram. Nota-se que houve um pequeno aumento no número de alunos que conseguiram elaborar um conceito para EA quando comparado com o pré-teste. Houve também uma maior diversidade de categorias ambientais representadas em seus conceitos. A categoria resolutiva ainda apresenta um maior número de citações (32\%), mas quando comparada com o pré-teste houve uma redução, levando a crer que estes alunos passaram a enxergar a EA não só como uma forma de resolver os problemas. A categoria de sensibilização manteve-se também como uma das mais citadas (21\%) e aumentou o seu percentual, o que demonstra uma percepção de que a EA é uma forma de comover os indivíduos quanto aos problemas ambientais. Outras categorias também foram citadas e os seus exemplos estão elucidados no Quadro 9.

Quadro 9: respostas dos alunos do grupo B da Escola Municipal Maria Pessoa Cavalcanti no questionário Pós-teste sobre o conceito de Educação Ambiental, categorizadas segundo Abílio (2011)

\begin{tabular}{|c|c|c|c|}
\hline \multirow[t]{2}{*}{ CORRENTES } & \multirow[t]{2}{*}{ EXEMPLOS } & \multicolumn{2}{|c|}{ ABUNDÂNCIA } \\
\hline & & Total & Relativa \\
\hline Resolutiva & $\begin{array}{l}\text { "Ajuda as pessoas a separar o lixo" } \\
\text { "Pode melhorar a terra" } \\
\text { "Porque não podemos poluir o meio ambiente" }\end{array}$ & 6 & $32 \%$ \\
\hline Sensibilização & $\begin{array}{l}\text { "Ajuda as pessoas para ter o cuidado do meio } \\
\text { ambiente" } \\
\text { "É saudável para nós e para o meio ambiente" }\end{array}$ & 4 & $21 \%$ \\
\hline $\begin{array}{l}\text { Desenvolvimento } \\
\text { Sustentável }\end{array}$ & $\begin{array}{l}\text { "Só assim a gente preserva para os nossos filhos } \\
\text { aprenderem também" }\end{array}$ & 1 & $5 \%$ \\
\hline Disciplina & "Para ajudar a gente a saber mais" & 2 & $11 \%$ \\
\hline Generalista & "Porque é bom" & 1 & $5 \%$ \\
\hline Preservacionista & "Porque o meio ambiente tem que ser preservado" & 1 & $5 \%$ \\
\hline Confuso & $\begin{array}{l}\text { "Porque Educação Ambiental é importante para a } \\
\text { nossa rua" } \\
\text { "Porque eles estão fazendo a parte deles" }\end{array}$ & 4 & $21 \%$ \\
\hline & & 19 & $100 \%$ \\
\hline
\end{tabular}

Fonte: Dados da pesquisa.

Revbea, São Paulo, V. 14, № 1: 416-438, 2019. 


\section{Análise comparativa grupo A e B}

Durante a pesquisa foi possível verificar que houveram diferenças no que concerne à percepção ambiental sobre o meio ambiente e a Educação Ambiental dos alunos que vivenciaram na prática a compostagem e a horta em relação àqueles que receberam apenas a palestra sobre o tema.

Após a sensibilização o grupo $A$, que vivenciou a compostagem $e$ aplicou o adubo na horta, ao ser questionado se no lixo que é descartado encontra-se algum material que ainda tenha utilidade, teve uma porcentagem maior de respostas "SIM" quando comparados ao grupo B, que assistiu apenas a palestra, como pode-se verificar no Quadro 10.

Quadro 10: Comparativo entre as repostas do grupo A e B da Escola Municipal Maria Pessoa Cavalcanti no questionário pós-teste frente ao questionamento se no lixo que é descartado encontramos algum material que ainda tenha utilidade.

\begin{tabular}{|l|c|c|}
\hline \multicolumn{1}{|c|}{ CATEGORIAS } & GRUPO A & GRUPO B \\
\hline Sim & $86 \%$ & $79 \%$ \\
\hline Não & $8 \%$ & $15 \%$ \\
\hline Não sabe/ Não respondeu & $6 \%$ & $6 \%$ \\
\hline
\end{tabular}

Fonte: dados da pesquisa.

No questionário pós-teste os alunos foram perguntados sobre compostagem e se reconheciam a sua importância. Para o grupo A $80 \%$ a consideram importante, enquanto que para o grupo $\mathrm{B}$ o resultado foi de $88 \%$, demonstrando similaridade no perfil das respostas. No entanto, quando solicitado para citar quais materiais poderiam ser utilizados para a compostagem no grupo A houveram $96 \%$ citações de sargaço e $58 \%$ restos de alimento, enquanto que no grupo B $79 \%$ sargaço e $82 \%$ restos de alimento. Verifica-se assim, que o grupo produtor do composto com sargaço quase que em sua totalidade aprendeu que é possível fazer compostagem com esse material, enquanto que o grupo da palestra ainda respondeu em sua maioria restos de alimento, pois, normalmente, quando se trata desse tema este é o material mais citado nos livros didáticos para essa finalidade. Tal proposição corrobora com o que diz Pavão e Leitão (2007) quando afirmam que os educadores precisam propor estratégias que permitam uma maior interatividade entre os alunos e o objeto de estudo, favorecendo assim uma aprendizagem significativa.

No tocante ao conceito de meio ambiente que foi analisado segundo Sauvé (2005), novamente pode-se verificar diferenças quanto aos resultados dos pós-testes dos grupos A e B. No grupo A, após a sensibilização, 96\% dos alunos foi capaz de elaborar um conceito para meio ambiente, já no grupo $B$ este resultado foi de $76 \%$. Com relação às correntes citadas, em ambos houve a predominância da naturalista, porém, no grupo $\mathrm{B}$ esse número foi maior. Assim como houve uma maior distribuição nas categorias no grupo $\mathrm{A}$ indicando

Revbea, São Paulo, V. 14, № 1: 416-438, 2019. 
que para este grupo houve uma maior ampliação da visão destes educandos no que diz respeito a esta temática, conforme pode-se observar no Quadro 11.

Quadro 11: Comparativo entre as repostas do grupo A e B da Escola Municipal Maria Pessoa Cavalcanti no questionário pós-teste sobre o conceito de Meio Ambiente categorizadas segundo Sauvé (2005).

\begin{tabular}{|l|c|c|}
\hline Correntes Meio Ambiente Sauvé (2005) & GRUPO A & GRUPO B \\
\hline Naturalista & $37 \%$ & $42 \%$ \\
\hline Conservacionista & $6 \%$ & $19 \%$ \\
\hline Resolutiva & $19 \%$ & $27 \%$ \\
\hline Biorregionalista & $15 \%$ & $12 \%$ \\
\hline Holística & $19 \%$ & - \\
\hline Moral/Ética & $2 \%$ & - \\
\hline Confuso & $2 \%$ & - \\
\hline
\end{tabular}

Fonte: dados da pesquisa.

Com relação à EA também se evidenciam diferenças entre os grupos. No questionário pós-teste $96 \%$ dos entrevistados do grupo A conseguiram elaborar um conceito para EA, no grupo B 56\%. As respostas foram categorizadas segundo Abílio (2011) e apesar da categoria resolutiva ser a mais abundante nos dois grupos, para o grupo $A$ houve um maior número de correntes citadas, uma maior distribuição e uma maior ênfase na categoria de sensibilização. No grupo B observamos também uma parcela significativa de respostas consideradas "confusas", como podemos verificar no Quadro 12.

Quadro 12: Comparativo entre as repostas do grupo A e B da Escola Municipal Maria Pessoa Cavalcanti no questionário pós-teste sobre o conceito de EA categorizadas segundo Abílio (2011)

\begin{tabular}{|l|c|c|}
\hline Categorias EA segundo Abílio (2011) & GRUPO A & GRUPO B \\
\hline Resolutiva & $38 \%$ & $32 \%$ \\
\hline Sensibilização & $29 \%$ & $21 \%$ \\
\hline Desenvolvimento sustentável & $4 \%$ & $5 \%$ \\
\hline Disciplina & $17 \%$ & $11 \%$ \\
\hline Generalista & $4 \%$ & $5 \%$ \\
\hline Preservacionista & $4 \%$ & $5 \%$ \\
\hline Conservacionista & $2 \%$ & - \\
\hline Confuso & $2 \%$ & $21 \%$ \\
\hline
\end{tabular}

Fonte: dados da pesquisa. 
Tais resultados reforçam a hipótese de que a vivência dos conteúdos através de atividades práticas, correlacionadas com a realidade dos educandos, proporciona uma melhor aprendizagem. Não basta o simples repasse de textos e exercícios contidos nos livros didáticos, nem tão pouco, ações isoladas como uma palestra. Fazem-se necessário estímulos constantes e permanentes, como os que puderam ser realizados através do trabalho com a compostagem e a horta.

É importante destacar que houve um maior período de sensibilização na atividade prática em relação à teórica, o que pode também ter contribuído para uma melhor assimilação dos conteúdos. Como também vale a pena salientar que para desenvolver uma atividade prática não se faz imprescindível o uso de um laboratório, com materiais simples, vontade e disponibilidade é possível tornar o ensino e a aprendizagem mais prazerosos e eficazes (ANDRADE; MASSABINI, 2011) e, desta forma, contribuir para a tão almejada melhoria da qualidade educacional do Brasil. Como diz Bassoli (2014) a insuficiente educação científica é remetida à ausência de atividades práticas na Educação Básica.

Cabe, portanto, ao professor reinventar-se e procurar novas rotas de aprendizagem para ministrar os conteúdos de forma lúdica e interativa, assim como, à direção e coordenação pedagógica oferecer estímulos e capacitação para tal.

\section{Considerações finais}

Os dados da pesquisa mostraram que apesar das temáticas meio ambiente e EA fazerem parte do conteúdo programático do sexto ano e já ter sido ministrada, a maioria dos alunos demonstrou dificuldade em reconhecer problemas ambientais como os relacionados com o lixo e as soluções ambientais como a compostagem no primeiro momento. Porém, após a sensibilização houve uma melhora na percepção dos problemas ambientais locais e suas possíveis soluções, sendo essa melhoria mais perceptível nos alunos que realizaram a atividade prática de compostagem e horta. Foi evidenciado que não basta apenas reproduzir as aulas propostas nos livros didáticos de forma teórica, é preciso diversificar, contextualizar e dinamizar este conteúdo, a fim de realizar uma aprendizagem efetiva e significativa.

A compostagem é uma ferramenta viável para ser executada nas escolas como forma de fazer Educação Ambiental, pois apresenta uma metodologia simples, de baixo custo e facilmente reproduzida.

É urgente repensar a EA nas escolas, pois elas são um espaço privilegiado para a construção do saber. Cabe aos educadores avaliarem a sua postura e a sua importância frente a um mundo que caminha para um caos ambiental e que tem na educação a sua última esperança. 


\section{Referências}

ABÍLIO, F.J.P. (Org.). Educação Ambiental para o Semiárido. João Pessoa: Editora Universitária da UFPB, 2011. 580p.

ANDRADE, M.L.F.; MASSABNI, V.G. O desenvolvimento de atividades práticas na escola: um desafio para os professores de ciências. Ciência \& Educação, Bauru, v. 17, n. 4, p. 835-854, 2011.

BARCELOS, V. Educação Ambiental: Sobre princípios, metodologias e atitudes. 2. ed. Petrópolis: Vozes, 2009.

BARDIN, L. Análise de Conteúdo. São Paulo: Edições 70, 2012

BASSOLI, F. Atividades práticas e o ensino-aprendizagem de ciência(s): mitos, tendências e distorções. Ciênc. Educ., v. 20, n. 3, p. 579-593, 2014.

CABRAL, F.F.; RIBEIRO, I.L.; HRYCYK, M.F.; Percepção ambiental de alunos do $6^{\circ}$ ano de escolas públicas. Revista Monografias Ambientais, v. 14, n. 2, p. 151-161, 2015.

CARVALHO, I.C.M. Educação Ambiental Crítica: Nomes e Endereçamentos da Educação. In: LAYRARGUES, P.P. (coord). Identidades da Educação Ambiental Brasileira, Brasília: MMA, 2004. cap. 1, p. 13-24.

CHAER, G.; DINIZ, R.R.P.; RIBEIRO, E. A. A técnica do questionário na pesquisa educacional. Evidência, v. 7, n. 7, p. 251-266, 2011.

IBGE População no último censo:, Censo Demográfico 2010

LAKATOS, E.M. Fundamentos de metodologia científica. 5. ed. São Paulo: Atlas, 2003.

LEITE, A.A.; ANDRADE, M.O.; CRUZ, D.D. Percepção ambiental do corpo docente e discente sobre os resíduos sólidos em uma escola pública no agreste paraibano. Remea, Rio Grande, v. 35, n.1, p. 58-75, 2018.

MACIEL, J.L.; WACHHOLZ, C.B.; ALMINHANA, C.O. BITAR, P.G.; MUHLE, R.P. Metodologias de uma Educação Ambiental Inclusiva. Revista EGP, v. 1, n. 1, 2010.

MENDES FILHO, O.R.; CALLOU, A.B.F.; SANTOS, M.S.T. Políticas públicas e extensão pesqueira em Cabedelo, Paraíba. Interações, v. 11, n. 1, p. 93-100, 2010.

MORIN, E. Os Sete Saberes necessários à educação do futuro. 8. ed. São Paulo: Cortez, 2003.

MORIN, E. A cabeça bem-feita: repensar a reforma, reformar o pensamento. Jacobina. 9. ed. Rio de Janeiro: Bertrand Brasil, 2004.

OLIVEIRA, M.S.; OLIVEIRA, B.S.; VILELA, M.C.S.; CASTRO, T.A.A. A importância da Educação Ambiental na escola e a reciclagem do lixo orgânico. Revista científica eletrônica de ciências sociais aplicadas do Vale de São Lourenço, v. 5, n. 7, 2012.

revista brasileira educação ambiental 
OLIVEIRA, F.R.; PEREIRA, E.R.; JÚNIOR, A.P. Horta escolar, Educação Ambiental e a interdisciplinaridade. Revbea, São Paulo, v. 13, n. 2, p. 10-31, 2018.

PAVÃO, A.C.; LEITÃO, A. Hands-on? Minds-on? Hearts-on? Social-on? Explainers-on! In: MASSARANI, L.; MERZAGORA, M.; RODARI, P. (Org.). Diálogos \& ciência: mediação em museus e centros de ciência. Rio de Janeiro: Museu da Vida, 2007. p. 39-46.

PIRES, P.; JUNIOR, R.C.R.; LEMOS, D.C.L.; FILGUEIRAS, A. Ecocentrismo e comportamento: revisão da literatura em valores ambientais. Psicologia em estudo. v. 19, n. 14, p. 611-620, 2014.

REIGOTA, M. Meio Ambiente e representação social. São Paulo: Cortez. 1995. 87p.

REIGOTA, M. O que é Educação Ambiental? São Paulo: Editora Brasiliense, 2010.

REPOLHO, S.M.; CAMPOS, D.N.S.; TAVARES-MARTINS, A.C.C.; ASSIS, D.M.S.; PONTES, A.N. Percepções ambientais e trilhas ecológicas: concepções de meio ambiente em escolas do município de Soure, Ilha de Marajo (PA). Revbea, São Paulo, v. 13, n. 2, p. 66-84, 2018.

SAUVÉ, L. Uma cartografia das correntes em Educação Ambiental. In: SATO, M.; CARVALHO, I.C.M. Educação Ambiental: pesquisa e desafios/ organizado por. - Porto Alegre: Artmed, 2005.

SILVA, E.A.; OLIVEIRA, C.A.M.; CUNHA, R.R.C.A.; SOARES, R.V.S.; TEIXEIRA, V.D.; GUENTHER, M. Educação Ambiental voltada para a reutilização e reciclagem dos resíduos sólidos no ambiente escolar: um estudo de caso no ensino fundamental em Recife (PE). Revbea, v. 9, n. 2, p. 412-423, 2014.

SOARES, A.M.D.; OLIVEIRA, L.M.T.; PORTILHO, E.S.; CORDEIRO, L.C.; CAVALCANTE, D.K. Educação Ambiental: construindo metodologias e práticas participativas. In: II Encontro da ANPPAS, 02., 2004, Indaiatuba. Anais do II Encontro da ANPPAS. Indaiatuba: ANPPAS, 2004.

TÉBAR, L. O perfil do professor mediador: pedagogia da mediação. São Paulo: Editora Senac São Paulo, 2011. 